\title{
Molecular Characterization of Coxsackievirus B5 Isolates from Sewage, Italy 2016-2017
}

\author{
Stefano Fontana ${ }^{1}$ - Stefano Fiore ${ }^{1} \cdot$ Gabriele Buttinelli $^{1} \cdot$ Concetta Amato $^{1} \cdot$ Licia Veronesi $^{2} \cdot$ Roberta Zoni $^{2}$. \\ Maria Triassi ${ }^{3}$. Francesca Pennino ${ }^{3}$. Giovanni Maurizio Giammanco ${ }^{4}$. Simona De Grazia ${ }^{4}$. Antonella Cicala ${ }^{5}$. \\ Angelo Siragusa ${ }^{5}$. Sabine Gamper ${ }^{6}$. Silvia Spertini ${ }^{6} \cdot$ Paolo Castiglia $^{7} \cdot$ Andrea Cossu $^{7} \cdot$ Cinzia Germinario $^{8}$. \\ Angela Maria Vittoria Larocca ${ }^{8} \cdot$ Paola Stefanelli $^{1}$
}

Received: 12 April 2019 / Accepted: 19 July 2019 / Published online: 26 July 2019

(c) The Author(s) 2019

\begin{abstract}
Hereby, the partial Viral Protein 1 sequences of Coxsackievirus B5 (CV-B5) from sewage samples, collected in Italy from 2016 to 2017, were compared with those available in GenBank from clinical samples. Phylogenetic analysis highlighted: (I) the predominant circulation of CV-B5 genogroup B in Italy, and (II) the presence of two new sub-genogroups.
\end{abstract}

Keywords Coxsackievirus $\cdot$ CV-B5 $\cdot$ Sewage $\cdot$ Non-polio enteroviruses $\cdot$ Phylogenetic analysis $\cdot$ Polioviruses

\section{Introduction}

Environmental surveillance (ES) provides an early warning system for a possible introduction of poliovirus and, since 1996, is one of the activities of the Italian WHO Collaborative Reference and Research Center for Polio (2015). Meanwhile, ES examines the circulation and the spatio-temporal distribution of non-polio enteroviruses (NPEVs; Pons-Salort

Paola Stefanelli

paola.stefanelli@iss.it

1 Department of Infectious Diseases, Italian National Institute of Health (Istituto Superiore di Sanità, ISS), Viale Regina Elena 299, 00161 Rome, Italy

2 Department of Medicine and Surgery, University of Parma, Parma, Italy

3 Department of Public Health, University of Naples Federico II, Naples, Italy

4 Department of Health Promotion, Mother and Child Care and Internal Medicine 'G. D’Alessandro', University of Palermo, Palermo, Italy

5 AMAP S.p.A, Palermo, Italy

6 Comprensorio Sanitario di Bolzano, Servizio Igiene e Sanità Pubblica, Bolzano, Italy

7 Department of Medical, Surgical and Experimental Sciences, University of Sassari, Sassari, Italy

8 Department of Biomedical Science and Human Oncology, University of Bari "Aldo Moro", Bari, Italy et al. 2018). In a recent study, our group analyzed more than 2800 sewage samples collected from 2009 to 2015. More than half of the samples were positive for NPEVs and Coxsackievirus B5 (CV-B5) being the most frequent serotype (Delogu et al. 2018).

Coxsackie B viruses are frequently associated with sporadic cases of neurological diseases, epidemics of meningitis, and chronic diseases such as cardiomyopathy and diabetes (Tracy and Gauntt 2008; Wikswo et al. 2009; Liu et al. 2014; Tao et al. 2014; Ma et al. 2013; Yao et al. 2017).

Henquell et al. (2013) described the genetic diversity of human CV-B5 clinical isolates with two main genogroups, $\mathrm{A}$ and $\mathrm{B}$, detected worldwide. Genogroup $\mathrm{A}$ is characterized by sequential acquisition of nonsynonymous changes in residues exposed at the virus 5-fold axis; genogroup B is marked by the selection of three changes in the VP1 C-terminus from its first emergence.

The main aim of this study was to type the NPEVs identified from sewage samples collected from 2016 to 2017 in Italy and to compare the partial VP1 target gene of Italian CV-B5 strains in order to determine their sub-grouping.

\section{Materials and Methods}

Sewage samples were collected from 17 inlets of wastewater treatment plants (WWTPs) serving the urban areas of Naples, Bolzano, Parma, Sassari, Bari, Palermo, Catania, 
Messina, Trapani, and Syracuse from 2016 to 2017. All samples, except those from Parma, were sent to the WHO collaborative center at the Istituto Superiore di Sanità (ISS), Rome, and were analyzed for the presence of Polioviruses and NPEVs. Samples from Parma were analyzed locally by the Sub-National Polio Reference Laboratory at the University of Parma. Molecular characterization of all polioviruses and NPEVs was performed at the ISS. Wastewater sampling and virus concentration were performed according the WHO Guidelines (2015). Briefly, wastewater samples were collected at the inlet collector, before treatment, and then concentrated by the two-phase separation method [polyethylene glycol (PEG)-dextran] obtaining an approximately 50-fold volume reduction. Seven WWTPs had a population equivalent greater than 300,000. At least 1 sample every 15 days for WWTPs serving $>300,000$ inhabitants and at least 1 sample every month for populations of $<300,000$ have been taken. An automatic $24 \mathrm{~h}$ sampling system was present in four inlets located in Napoli, Palermo, and Bolzano. Manual sampling was performed early in the morning (peak hours) in the remaining cities. Concentrated sewage was inoculated both on RD (human rhabdomyosarcoma cells) and on L20B (genetically modified murine cell line L-series) cell monolayers and analyzed for poliovirus and NPEVs, according to the WHO algorithm (2015).

Viral RNAs were extracted from $200 \mu$ of cell lysate from samples with cellular cytopathic effect using Viral Nucleic Acid Extraction Kit II (Geneaid, New Taipei, Taiwan), according to the manufacturer's instruction. RT-nested-PCR was performed as previously described with slight modifications: the first amplification step was performed with 222/224 oligonucleotides and the second with AN88/AN89 (Nix et al. 2006; CDC-WHO 2015). Briefly, the first PCR round was carried out using the Access RT-PCR System kit (Promega, Madison, Wisconsin, USA) with an initial reverse transcription step at $45{ }^{\circ} \mathrm{C}$ for $40 \mathrm{~min}$, followed by $94{ }^{\circ} \mathrm{C}$ for $2 \mathrm{~min}, 40$ cycles at $94{ }^{\circ} \mathrm{C}$ for $30 \mathrm{~s}, 42^{\circ} \mathrm{C}$ for $45 \mathrm{~s}, 68^{\circ} \mathrm{C}$ for $60 \mathrm{~s}$, and a final extension at $72{ }^{\circ} \mathrm{C}$ for $5 \mathrm{~min}$. Second round was performed using GOTAQ Green 2X Master G2 kit (Fisher Molecular Biology, Rome, Italy) at the following conditions: $95{ }^{\circ} \mathrm{C}$ for $30 \mathrm{~s}$, followed by 40 cycles at $95{ }^{\circ} \mathrm{C}$ for $30 \mathrm{~s}, 60^{\circ} \mathrm{C}$ for $20 \mathrm{~s}, 72{ }^{\circ} \mathrm{C} 30 \mathrm{~s}$, and a final extension for 5 min at $72{ }^{\circ} \mathrm{C}$. GeneAmp ${ }^{\circledR}$ PCR System 9700 thermal cycler (Applied Biosystems, Inc., Foster City, CA) was used for both rounds. The final amplification products, separated on $1.2 \%$ agarose gel stained with GelRed ${ }^{\circledR}$ (Biotium, Fremont, California, USA), were inspected with Molecular Imager ${ }^{\circledR}$ Gel Doc ${ }^{\mathrm{TM}}$ XR using the Quantity-One ${ }^{\circledR}$ software (BioRad, Segrate, Italy). Sanger nucleotide sequencing of partial VP1 gene (319 nucleotides) was also performed using the AN88/ AN89 primers on the nested-PCR products. Sequence analysis and comparison was achieved with software Sequencer ${ }^{\circledR}$ 5.2 (Gene Codes Corporation, Ann Arbor, Michigan, USA) and NCBI GenBank (http://www.ncbi.nlm.nih.gov). The sequences were aligned together with $11 \mathrm{VP} 1$ sequences of CV-B5 genogroups A and 9 of CV-B5 of genogroup B published by Henquell et al. (2013). A phylogenetic tree, based on the 319 nucleotides of the VP1 region, was constructed using MEGA6 software (www.megasoftware.net) following the maximum likelihood method (Kimura 2-parameter model, gamma distributed).

\section{Results}

Overall, 423 sewage samples were collected, of which 244 were NPEV-positive by the cellular cytopathic effect on the RD cell line.

Half of the NPEV-positive samples (122/244) were selected for viral typing. In particular, for each Italian city participating in the surveillance we selected, in the period (2016-2017), half of their NPEVs positive samples. The most frequent genotype was CV-B5 (26.2\%, 32/122), followed by Echovirus (E)-6 (22.10\%, 27/122), E-11 (12.30\%; 15/122), and CV-B3 (11.5\%, 14/122). The remaining 34 isolates belonged to 10 different genotypes: E-13 (7.38\%), CVB-B4 (5.74\%), E-25 (4.92\%), E-7 (4.10\%), E-3 (1.64\%), E-30 (0.82\%), CVB-B2 (0.82\%), E-9 (0.82\%), E-20 (0.82\%), and E-19 (0.82\%). One Sabin-like poliovirus type 3 strain was isolated from the WWTPs plant serving the urban area of Parma in October 2017.

Partial VP1 sequences (nt 2556 to 2874 of CV-B5 strain Faulkner complete genome) from 32 Italian CV-B5 strains, identified in sewage concentrates, were compared with 20 VP1 sequences representative of the $8 \mathrm{CV}$-B5 sub-genogroups described by Henquell et al. from clinical samples, available in GenBank (https://www.ncbi.nlm.nih.gov/genba nk/), from 10 countries over a long time period (1977-2009, Table 1).

Figure 1 shows the genetic relationship among 52 VP1 sequences; moreover, the sequences of CV-B5 Faulkner and CV-B3 reference strains were also included.

Two VP1 Italian CV-B5 sequences, from sewage samples in the urban area of Naples, grouped with VP1 CV-B5 Faulkner reference strain within the genogroup A, being similar to the sub-genogroup A4 (Fig. 1). The remaining 30 Italian VP1 sequences, in the B branch together with VP1 sequences of genogroup B CV-B5 strains by Henquell et al., splitted into two novel sub-groups (B3 and B4). In fact, the genetic distance between the two newly described CV-B5 sub-groups (Italian samples) was estimated at 12.3\%; while, B3 and B4 sub-groups differed from the sub-genogroups B described by Henquell et al. (sub-genogroups B0, $\mathrm{B} 1$ and B2) for 15.2 to 9.6 and for 15.5 to $9.3 \%$, respectively. As a reference, the distance among sub-genogroups B described by Henquell et al. ranged from 6.9 to $13.1 \%$. No 
Table 1 Details of the CV-B5 Viral Protein 1 sequences used in the study

\begin{tabular}{|c|c|c|c|c|c|c|c|c|}
\hline ID & $\begin{array}{l}\text { Accession } \\
\text { number }\end{array}$ & $\begin{array}{l}\text { Genogroup/ } \\
\text { sub-geno- } \\
\text { group }\end{array}$ & Type of sample & $\begin{array}{l}\text { Country } \\
\text { of origin }\end{array}$ & $\begin{array}{l}\text { City of isola- } \\
\text { tion }\end{array}$ & $\begin{array}{l}\text { Year of isola- } \\
\text { tion }\end{array}$ & $\begin{array}{l}\text { Month of isola- } \\
\text { tion }\end{array}$ & $\begin{array}{l}\text { Number of } \\
\text { sampling per } \\
\text { months }\end{array}$ \\
\hline CF807S & HF948028 & AO & Clinical & $F R A$ & Not reported & 1977 & Not reported & Not applicable \\
\hline CF595 & HF948121 & $A 1$ & Clinical & $F R A$ & Not reported & 1999 & Not reported & Not applicable \\
\hline 17036 & GU300063 & $A 1$ & Clinical & $N L D$ & Not reported & 1996 & Not reported & Not applicable \\
\hline STU108 & HF948077 & $A 1$ & Clinical & $D E U$ & Not reported & 2004 & Not reported & Not applicable \\
\hline P028 & GU300060 & $A 2$ & Clinical & $P A K$ & Not reported & 1990 & Not reported & Not applicable \\
\hline$C F 219051$ & HF948037 & $A 3$ & Clinical & $F R A$ & Not reported & 2006 & Not reported & Not applicable \\
\hline LIM004 & HF948229 & $A 3$ & Clinical & $C Y P$ & Not reported & 1996 & Not reported & Not applicable \\
\hline GRE447 & HF948173 & $A 3$ & Clinical & $F R A$ & Not reported & 2003 & Not reported & Not applicable \\
\hline CF186106 & HF948132 & $A 4$ & Clinical & $F R A$ & Not reported & 2005 & Not reported & Not applicable \\
\hline СОРТ11098 & HF948070 & $A 4$ & Clinical & $D N K$ & Not reported & 2008 & Not reported & Not applicable \\
\hline YZ032 & $G Q 246515$ & A4 & Clinical & CHN & Not reported & 2005 & Not reported & Not applicable \\
\hline CF641 & HF948115 & BO & Clinical & $F R A$ & Not reported & 1979 & Not reported & Not applicable \\
\hline 614 & GU300052 & BO & Clinical & FIN & Not reported & 1984 & Not reported & Not applicable \\
\hline 3939 & GU300050 & BO & Clinical & $U S A$ & Not reported & 1982 & Not reported & Not applicable \\
\hline BES1550 & HF948149 & $B 1$ & Clinical & $F R A$ & Not reported & 2000 & Not reported & Not applicable \\
\hline 119229 & FJ868290 & $B 1$ & Clinical & $A U S$ & Not reported & 1992 & Not reported & Not applicable \\
\hline COPT50075 & HF948263 & $B 1$ & Clinical & $D N K$ & Not reported & 1993 & Not reported & Not applicable \\
\hline BOL36 & HF948065 & $B 2$ & Clinical & ITA & Not reported & 2008 & Not reported & Not applicable \\
\hline NICOO1 & HF948245 & $B 2$ & Clinical & $C Y P$ & Not reported & 2009 & Not reported & Not applicable \\
\hline STU6 & HF948275 & $B 2$ & Clinical & $D E U$ & Not reported & 2009 & Not reported & Not applicable \\
\hline BZ-16-32 & MK517444 & B4 & Environmental & ITA & Bolzano & 2016 & September & 2 \\
\hline BZ-16-36 & MK517473 & B4 & Environmental & ITA & Bolzano & 2016 & November & 2 \\
\hline BZ-16-45 & MK517445 & B3 & Environmental & ITA & Bolzano & 2016 & December & 2 \\
\hline BZ-17-02 & MK517446 & B3 & Environmental & ITA & Bolzano & 2017 & January & 2 \\
\hline BZ-17-11 & MK517443 & B4 & Environmental & ITA & Bolzano & 2017 & March & 2 \\
\hline BZ-17-23 & MK517447 & B4 & Environmental & ITA & Bolzano & 2017 & June & 2 \\
\hline 1CAI-17-01 & MK517470 & B3 & Environmental & ITA & Catania & 2017 & June & 2 \\
\hline 1CAI17-02 & MK517448 & B3 & Environmental & ITA & Catania & 2017 & June & 2 \\
\hline 1CAI-17-03 & MK517449 & B3 & Environmental & ITA & Catania & 2017 & August & 2 \\
\hline 1CAI-17-04 & MK517450 & B3 & Environmental & ITA & Catania & 2017 & July & 2 \\
\hline 1CAI-17-06 & MK517451 & B3 & Environmental & ITA & Catania & 2017 & July & 2 \\
\hline 2CAI-17-25 & MK517452 & B3 & Environmental & ITA & Catania & 2017 & September & 2 \\
\hline 2CAI-17-27 & MK517453 & B4 & Environmental & ITA & Catania & 2017 & October & 2 \\
\hline E276 & MK517454 & B4 & Environmental & ITA & Parma & 2017 & December & 2 \\
\hline E277 & MK517455 & B4 & Environmental & ITA & Parma & 2017 & December & 2 \\
\hline E278 & MK517457 & B4 & Environmental & ITA & Parma & 2017 & January & 2 \\
\hline E279 & MK517458 & B3 & Environmental & ITA & Parma & 2017 & January & 2 \\
\hline $\mathrm{O} 277$ & MK517456 & B4 & Environmental & ITA & Parma & 2017 & December & 2 \\
\hline $\mathrm{O} 278$ & MK517464 & B4 & Environmental & ITA & Parma & 2017 & January & 2 \\
\hline E281 & MK517459 & B3 & Environmental & ITA & Parma & 2017 & February & 2 \\
\hline 1NA-16-18 & MK517471 & B4 & Environmental & ITA & Napoli & 2016 & February & 3 \\
\hline 2NA-16-21 & MK517472 & A4 & Environmental & ITA & Napoli & 2016 & February & 2 \\
\hline 1NA-16-23 & MK517460 & B4 & Environmental & ITA & Napoli & 2016 & February & 3 \\
\hline 2NA-16-28 & MK517461 & A4 & Environmental & ITA & Napoli & 2016 & March & 2 \\
\hline 1NA-16-29 & MK517474 & B4 & Environmental & ITA & Napoli & 2016 & March & 3 \\
\hline 1NA-17-50 & MK517462 & B3 & Environmental & ITA & Napoli & 2017 & June & 3 \\
\hline 1NA-17-58 & MK517463 & B3 & Environmental & ITA & Napoli & 2017 & February & 3 \\
\hline 2PA-16-79 & MK517465 & B3 & Environmental & ITA & Palermo & 2016 & December & 2 \\
\hline
\end{tabular}


Table 1 (continued)

\begin{tabular}{|c|c|c|c|c|c|c|c|c|}
\hline ID & $\begin{array}{l}\text { Accession } \\
\text { number }\end{array}$ & $\begin{array}{l}\text { Genogroup/ } \\
\text { sub-geno- } \\
\text { group }\end{array}$ & Type of sample & $\begin{array}{l}\text { Country } \\
\text { of origin }\end{array}$ & $\begin{array}{l}\text { City of isola- } \\
\text { tion }\end{array}$ & $\begin{array}{l}\text { Year of isola- } \\
\text { tion }\end{array}$ & $\begin{array}{l}\text { Month of isola- } \\
\text { tion }\end{array}$ & $\begin{array}{l}\text { Number of } \\
\text { sampling per } \\
\text { months }\end{array}$ \\
\hline 1PA-17-06 & MK517466 & B3 & Environmental & ITA & Palermo & 2017 & January & 2 \\
\hline 2PA-17-10 & MK517467 & B4 & Environmental & ITA & Palermo & 2017 & February & 2 \\
\hline 3PA-17-20 & MK517468 & B3 & Environmental & ITA & Palermo & 2017 & March & 1 \\
\hline SS-17-06 & MK517469 & B4 & Environmental & ITA & Sassari & 2017 & March & 2 \\
\hline
\end{tabular}

In italics the data published by Henquell et al. (2013)

Fig. 1 Phylogenetic tree based on the partial VP1 (nt 2556 to 2874 of CV-B5 strain Faulkner complete genome) nucleotide sequences. Trees were built using the maximum likelihood method (Kimura 2-parameter), and bootstrapped with 100 repetitions. Filled circles Italian sewages samples, open triangles genogroup B clinical samples described by Henquell et al. (2013), open squares genogroup A clinical samples described by Henquell et al. (2013)

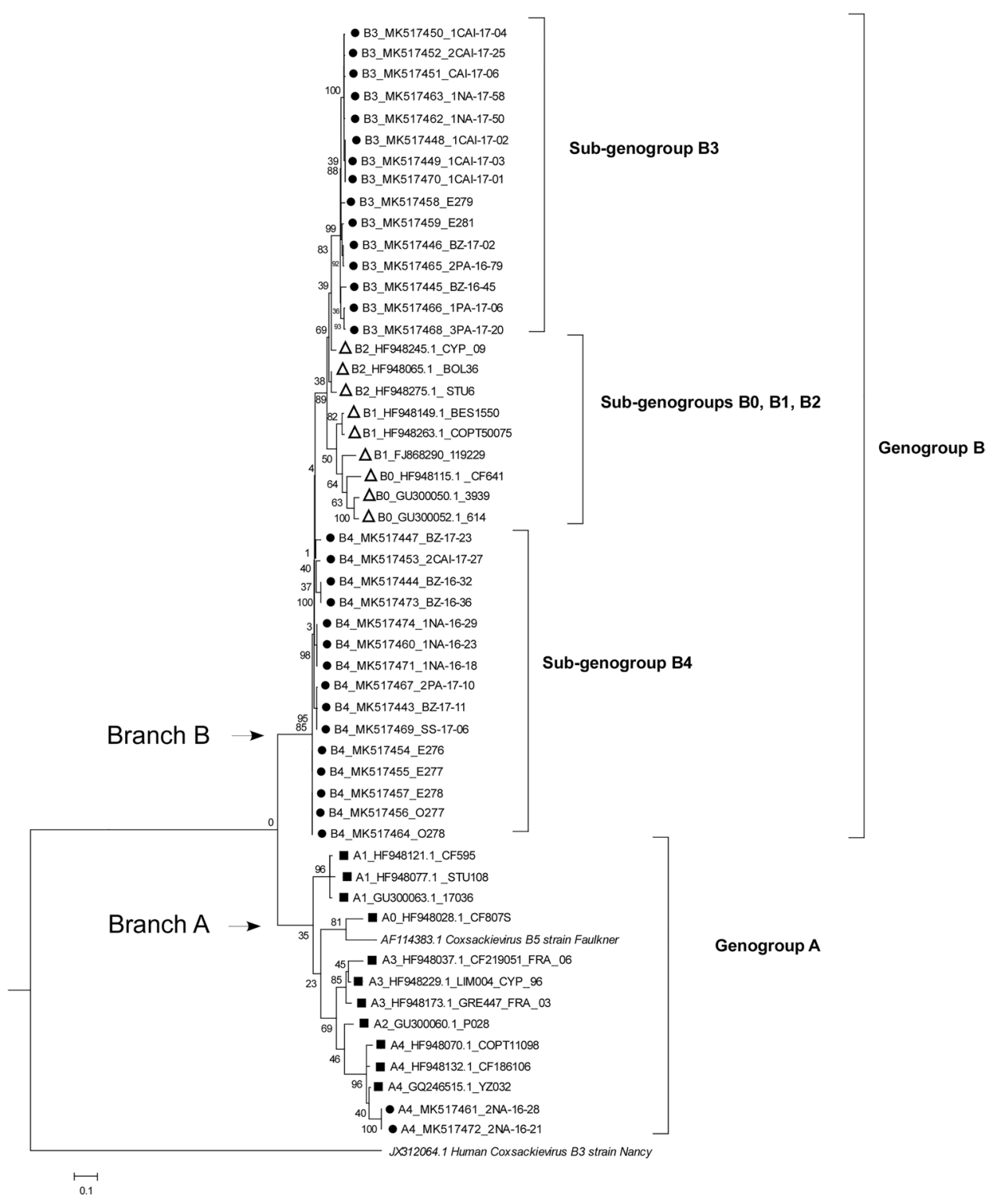


relationships were found between the novel B sub-groups and geographic location of the sewage samples.

\section{Discussion}

ES, which is critical to support the global polio eradication endgame, permit to provide early detection of human enteric pathogens excreted with stools during an infection. Several studies reported a clear correlation between the isolation of enteroviruses in sewage, the isolation in humans, and clinical cases identified in the community (Nelson et al. 1967; Manor et al. 1999; Bisseux et al. 2018). All the NPEVs, here described, belonged to the species B, in agreement with what already found in sewage samples collected in Europe (Majumdar et al. 2018). Of note, it is the routine use of RD cell lines that follow the WHO protocol (2015), which favor for the isolation mainly of the EV species B (Majumdar et al. 2018).

The partial sequencing of VP1 was used to determine the serotype and to genetically analyze CV-B5 Italian strains detected in sewages versus CV-B5 strains from clinical samples (Henquell et al. 2013).

The phylogenetic analysis of a 319 nucleotides fragment of VP1 revealed a predominant circulation of genogroup B CV-B5 strains in Italy. This genogroup showed a low rate of evolution in the antigenic determinants over the last 50 years (Henquell et al. 2013).

However, phylogenetic analysis segregated the genogroup B Italian sequences into two relatively distant subgroups. The marked genetic divergence between the two Italian sequence-clusters and each of the three previously described sub-genogroups, suggests us to consider them as two novel CV-B5 sub-genogroups, namely B3 and B4. Due to the short sampling time period and high genetic conservation of VP1 region, the Italian CV-B5 sequences within sub-genogroups B3 and B4 resulted very similar with a low genetic distance (from 0.00 to $4.00 \%$ ). In some cases (e.g., IDs E276, E277, E278) the VP1 sequences of the samples collected at the same site and at a short distance of time in the sampling were identical.

Hereby, the main findings are in agreement with what already described in Italy (Delogu et al.) in a more comprehensive sample size collected from 2009 to 2015. Moreover, the predominant circulation of CV-B5 of genogroup B was characterized by the presence of new subgroups evolving or being recently introduced in Italy.

As in many other European countries, also in Italy the real burden of EV disease can't be affordably calculated due to many factors including viral diagnosis not always available for central nervous system diseases, pericarditis or cardiomyopathy, and for many other diseases like hand-foot-and-mouth disease or herpangina. Our results emphasize the need for improving national EV surveillance including genetic characterization of the virus isolated in Italy.

Acknowledgements The authors thank the Italian Ministry of Health and the Regional Reference Labs in Italy for the collaboration to the Environmental Surveillance System. The authors are also grateful to Laura Pellegrinelli and Sandro Binda (Department of Biomedical Sciences for Health, University of Milan, Italy) for their Environmental Surveillance support.

Funding This work was partially supported by Grant from WHO "Full providing of laboratory support for surveillance of polioviruses in Acute Flaccid Paralysis Cases and in the Environment from specified European Countries". Environmental sampling in Catania, Messina, Trapani, and Syracuse was partly supported by the Italian Ministry of Health through the Grants: "Linea progettuale ${ }^{\circ} 18.6$ dei Progetti Obiettivo di Piano Sanitario Nazionale - anno 2013" and "Linea progettuale ${ }^{\circ} 4.9 .3$ dei Progetti Obiettivo di Piano Sanitario Nazionale - anno 2016 - Monitoraggio ambientale della circolazione di virus patogeni a trasmissione fecale-orale come indicatore dello stato di salute della popolazione e come strumento per la programmazione e la valutazione di efficacia degli interventi di sanità pubblica."

\section{Compliance with Ethical Standards}

Conflicts of interest The authors declare that there are no conflicts of interest.

Ethical Approval and Informed Consent Not applicable.

Open Access This article is distributed under the terms of the Creative Commons Attribution 4.0 International License (http://creativeco mmons.org/licenses/by/4.0/), which permits unrestricted use, distribution, and reproduction in any medium, provided you give appropriate credit to the original author(s) and the source, provide a link to the Creative Commons license, and indicate if changes were made.

\section{References}

Bisseux, M., Colombet, J., Mirand, A., Roque-Afonso, A. M., Abravanel, F., Izopet, J., et al. (2018). Monitoring human enteric viruses in wastewater and relevance to infections encountered in the clinical setting: A one-year experiment in central France, 2014 to 2015. Eurosurveillance. https://doi.org/10.2807/1560-7917. es.2018.23.7.17-00237.

CDC-WHO. (2015). Enterovirus surveillance guidelines. Guidelines for enterovirus surveillance in support of the Polio Eradication Initiative.

Delogu, R., Battistone, A., Buttinelli, G., Fiore, S., Fontana, S., Amato, C., et al. (2018). Poliovirus and other enteroviruses from environmental surveillance in Italy, 2009-2015. Food and Environmental Virology, 10(4), 333-342. https://doi.org/10.1007/s1256 0-018-9350-8. Epub 2018 June 12.

Henquell, C., Mirand, A., Richter, J., Schuffenecker, I., Böttiger, B., Diedrich, S., et al. (2013). Phylogenetic patterns of human Coxsackievirus B5 arise from population dynamics between two genogroups and reveal evolutionary factors of molecular adaptation and transmission. Journal of Virology, 87(22), 12249-12259. https://doi.org/10.1128/jvi.02075-13. Epub 2013 Sep 4. 
Liu, N., Jia, L., Yin, J., Wu, Z., Wang, Z., Li, P., et al. (2014). An outbreak of aseptic meningitis caused by a distinct lineage of Coxsackievirus B5 in China. International Journal of Infectious Diseases, 23, 101-104. Erratum in: International Journal of Infectious Diseases, 33, 227. https://doi.org/10.1016/j.ijid.2014.02.005 (Epub 2014 April 16).

Ma, H., Huang, X., Kang, K., Li, X., Tang, X., Ren, Y., et al. (2013). Recombination in human Coxsackievirus B5 strains that caused an outbreak of viral encephalitis. Archives of Virology, 158(10), 2169-2173. https://doi.org/10.1007/s00705-013-1709-4. Epub 2013 April 28.

Majumdar, M., Sharif, S., Klapsa, D., Wilton, T., Alam, M. M., Fernandez-Garcia, M. D., et al. (2018). Environmental surveillance reveals complex enterovirus circulation patterns in human populations. Open Forum Infectious Diseases, 5(10), ofy250. https://doi. org/10.1093/ofid/ofy250. eCollection 2018 Oct.

Manor, Y., Handsher, R., Halmut, T., Neuman, M., Bobrov, A., Rudich, H., et al. (1999). Detection of poliovirus circulation by environmental surveillance in the absence of clinical cases in Israel and the Palestinian authority. Journal of Clinical Microbiology, 37(6), $1670-1675$.

Nelson, D. B., Circo, R., \& Evans, A. S. (1967). Strategic viral surveillance of sewage during and following an oral poliovirus vaccine campaign. American Journal of Epidemiology, 86(3), 641-652.

Nix, W. A., Oberste, M. S., \& Pallansch, M. A. (2006). Sensitive, seminested. PCR amplification of VP1 sequences for direct identification of all enterovirus serotypes from original clinical specimens. Journal of Clinical Microbiology, 44(8), 2698-2704.

Pons-Salort, M., Oberste, M. S., Pallansch, M. A., Abedi, G. R., Takahashi, S., Grenfell, B. T., et al. (2018). The seasonality of non-polio enteroviruses in the United States: Patterns and drivers. Proceedings of National Academy of Sciences of USA, 115(12), 3078-3083. https://doi.org/10.1073/pnas.1721159115. Epub 2018 March 5.

Tao, Z., Wang, H., Liu, Y., Li, Y., Jiang, P., Liu, G., et al. (2014). Non-polio enteroviruses from acute flaccid paralysis surveillance in Shandong Province, China, 1988-2013. Scientific Reports, 4, 6167. https://doi.org/10.1038/srep06167.

Tracy, S., \& Gauntt, C. (2008). Group B Coxsackievirus virulence. Current Topics in Microbiology and Immunology, 323, 49-63. Review.

WHO. (2015). Global Polio Eradication Initiative-Guidelines on environmental surveillance for detection of polioviruses, March 2015.

Wikswo, M. E., Khetsuriani, N., Fowlkes, A. L., Zheng, X., Peñaranda, S., Verma, N., et al. (2009). Increased activity of coxsackievirus B1 strains associated with severe disease among young infants in the United States, 2007-2008. Clinical Infectious Diseases, 49, e44-e51.

Yao, X., Bian, L. L., Lu, W. W., Li, J. X., Mao, Q. Y., Wang, Y. P., et al. (2017). Epidemiological and etiological characteristics of herpangina and hand foot mouth diseases in Jiangsu, China, 2013-2014. Human Vaccines and Immunotherapeutics, 13(4), 823-830. https ://doi.org/10.1080/21645515.2016.1236879. Epub 2016 Oct 21.

Publisher's Note Springer Nature remains neutral with regard to jurisdictional claims in published maps and institutional affiliations. 